\title{
Management of Liver Tumors during the COVID-19 Pandemic: The Added Value of Selective Internal Radiation Therapy (SIRT)
}

\author{
Irene Bargellini ${ }^{1, *}\left(\mathbb{0}\right.$, Giuseppe Boni ${ }^{2}$, Antonio Claudio Traino ${ }^{3}$, Elena Bozzi ${ }^{1}$, Giulia Lorenzoni ${ }^{1}$, \\ Francesca Bianchi ${ }^{2}$, Rosa Cervelli ${ }^{1}$, Tommaso Depalo ${ }^{2}$, Laura Crocetti ${ }^{1}$, Duccio Volterrani ${ }^{2} \mathbb{D}$ and Roberto Cioni ${ }^{1}$ \\ 1 Department of Interventional Radiology, Pisa University Hospital, 56126 Pisa, Italy; \\ elenabozzi@libero.it (E.B.); lorenzoni.giulia@hotmail.it (G.L.); rosacervelli.med@gmail.com (R.C.); \\ laura.crocetti@med.unipi.it (L.C.); r.cioni@ao-pisa.toscana.it (R.C.) \\ 2 Department of Nuclear Medicine, Pisa University Hospital, 56126 Pisa, Italy; bonigb@yahoo.it (G.B.); \\ fbianchimednuc@yahoo.it (F.B.); tom.depalo@gmail.com (T.D.); duccio.volterrani@unipi.it (D.V.) \\ 3 Department of Health Physics, Pisa University Hospital, 56126 Pisa, Italy; c.traino@ao-pisa.toscana.it \\ * Correspondence: irenebargellini@hotmail.com; Tel.: +39-05099-6961
}

Citation: Bargellini, I.; Boni, G.; Traino, A.C.; Bozzi, E.; Lorenzoni, G.; Bianchi, F.; Cervelli, R.; Depalo, T.; Crocetti, L.; Volterrani, D.; et al. Management of Liver Tumors during the COVID-19 Pandemic: The Added Value of Selective Internal Radiation Therapy (SIRT). J. Clin. Med. 2021, 10, 4315. https://doi.org/10.3390/ jcm10194315

Academic Editors: Massimo Venturini and Federico Fontana

Received: 12 August 2021

Accepted: 20 September 2021

Published: 22 September 2021

Publisher's Note: MDPI stays neutral with regard to jurisdictional claims in published maps and institutional affiliations.

Copyright: (c) 2021 by the authors. Licensee MDPI, Basel, Switzerland. This article is an open access article distributed under the terms and conditions of the Creative Commons Attribution (CC BY) license (https:/ / creativecommons.org/licenses/by/ $4.0 /)$.

\begin{abstract}
Background: In the context of the coronavirus disease 2019 (COVID-19) pandemic, liverdirected therapies (LDTs) may offer minimally invasive integrative tools for tumor control. Among them, selective internal radiation therapy (SIRT) represents a safe, flexible and effective treatment. Purpose of this study is to present our experience with SIRT during the first wave of COVID-19 pandemic and provide an overview of the indications and challenges of SIRT in this scenario. Methods: We retrospectively analyzed the number of patients evaluated by Multidisciplinary Liver Tumor Board (MLTB) and who were undergoing LDTs between March and July 2020 and compared it with 2019. For patients treated with SIRT, clinical data, treatment details and the best radiological response were collected. Results: Compared to 2019, we observed a 27.5\% reduction in the number of patients referred to MLTB and a $28.3 \%$ decrease in percutaneous ablations; transarterial chemoembolizations were stable, while SIRT increased by $64 \%$. The majority of SIRT patients $(75 \%)$ had primary tumors, mostly HCC. The best objective response and disease control rates were $56.7 \%$ and $72.2 \%$, respectively. Conclusion: The first wave of the COVID-19 pandemic was characterized by an increased demand for SIRT, which represents a safe, flexible and effective treatment, whose manageability will further improve by simplifying the treatment workflow, developing user-friendly and reliable tools for personalized dosimetry and improving interdisciplinary communication.
\end{abstract}

Keywords: radioembolization; yttrium; holmium; hepatocellular carcinoma; cholangiocarcinoma; liver cancer; metastases; COVID-19; pandemic

\section{Introduction}

The worldwide occurrence of the coronavirus disease 2019 (COVID-19) pandemic is having a profound effect on the management of cancer patients. Delays have been reported in referrals, screenings, diagnoses, surgical programs and follow-ups, as well as modifications of systemic treatments' regimens, suspensions and difficulties in accessing clinical trials and progressive implementation of treatments allowing for self-care management and remote consultations [1-4].

Over the past years, liver-directed therapies (LDTs), such as percutaneous ablation and transarterial treatments, have received wide recognition in international guidelines, both for primary and metastatic liver lesions [5-8]. Low invasiveness, safety and good local tumor control, limited resource consumption and possible combination with other local and systemic therapies represent major advantages of LDTs. In the context of the COVID-19 pandemic, LDTs have become an essential tool for the management of cancer patients. Among LDTs, intra-arterial selective internal radiation therapy (SIRT) represents a safe, well-tolerated and effective treatment option in well-selected, non-surgical patients 
with radiosensitive liver tumors, provided adequate tumor targeting and that a sufficient radiation dose is delivered to the tumor [9-14].

Purpose of this study is to analyze the utilization of SIRT in liver cancer patients during the first wave of the COVID-19 pandemic, and to provide an overview of the indications and the challenges of SIRT in this new scenario.

\section{Materials and Methods}

In Italy, the COVID-19 outbreak forced a first lockdown from March to May 2020, allowing only patients in emergency situations access to care as well as oncologic patients at high risk of early progression, defined as those requiring treatment within 30 days.

In our tertiary referral university hospital, this period was characterized by a sudden block in patients' referrals, reduced access to any procedure requiring anesthesiologic support, lack of blood donations and forced annulment of surgical and transplantation procedures.

Despite this situation, selected oncologic activities were maintained, including some loco-regional therapies not requiring anesthesiologic support, blood transfusions and longer hospitalization.

We retrospectively reviewed the registries of our weekly Multidisciplinary Liver Tumor Board (MLTB) to assess the number of patients who were evaluated from March (when the lockdown started) until July 2020 (to include the phase of exiting the lockdown) and compared it with the same period of time in 2019. Our electronic database was searched to assess the number of LDTs performed after MLTB discussion in the same period of time. LDTs included percutaneous ablation, transarterial chemoembolization (TACE) and SIRT.

For patients treated with SIRT, demographic and clinical data were collected, including tumor histology and stage, indications for SIRT and treatment modality.

\subsection{SIRT Workflow}

SIRT was preceded by a simulation procedure consisting of an angiographic study, with transfemoral arterial access, to detect arterial feeders supplying the lesions and any extrahepatic branches requiring preventive embolization.

After the catheter was placed in its final position, Technetium-99m macroaggregated albumin (Tc-99m MAA) or scout dose Holmium-166-labeled particles were injected intraarterially, and SPECT-CT was performed to assess hepato-pulmonary shunting, extrahepatic depositions and target lesion uptake and to perform dosimetric calculations.

The treatment was performed 1-3 weeks after the preliminary evaluation, placing the microcatheter in the planned position and administering the radiolabeled microspheres (SirSphere ${ }^{\circledR}$, Sirtex Medical Europe GmbH, Bonn, Germany; TheraSphere ${ }^{\circledR}$, Boston Scientific, Marlborough, MA, USA; QuiremSpheres ${ }^{\circledR}$, Terumo Europe NV, Leuven, Belgium).

In case of bilobar disease, the treatment of each lobe was performed in separate sessions, at an interval of 4-6 weeks.

\subsection{Follow-Up}

Patients were discharge 24-48 h after the procedure. Clinical and radiological followup was performed at 45 days and every 3 months thereafter. Imaging follow-up was performed by CT and/or MR.

For the present study, the best radiological tumor response was collected only for patients treated in 2020, and it was assessed according to the Response Evaluation Criteria for Solid Tumors (RECIST) 1.1 [15] for metastatic lesions and intrahepatic cholangiocarcinoma (iCC) and modified RECIST (mRECIST) [16] for hepatocellular carcinoma.

\subsection{Statistical Analysis}

Data were analyzed using descriptive statistics (mean and standard deviation, SD) and compared with the Chi-square or Fisher's exact test for categorical data and Student's $t$-test for paired data. Statistical analysis was carried out with dedicated software (SAS, Cary, NC, USA) considering a $p$ value $<0.05$ as statistically significant. 


\section{Results}

Between March and July 2020, 353 cases were discussed at the MLTB, compared to 487 cases of 2019, resulting in 27.5\% reduction; this decrease was more evident in April and May with a slow resumption after May 2020 (Figure 1a).

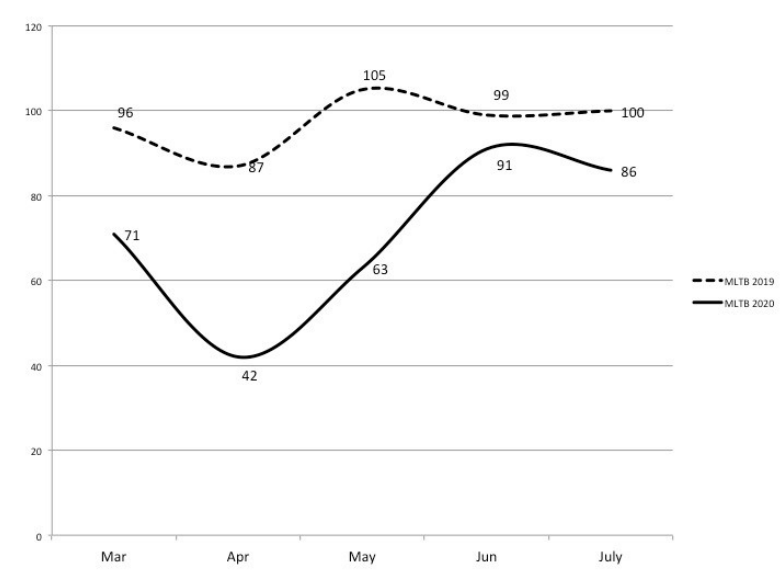

(a)

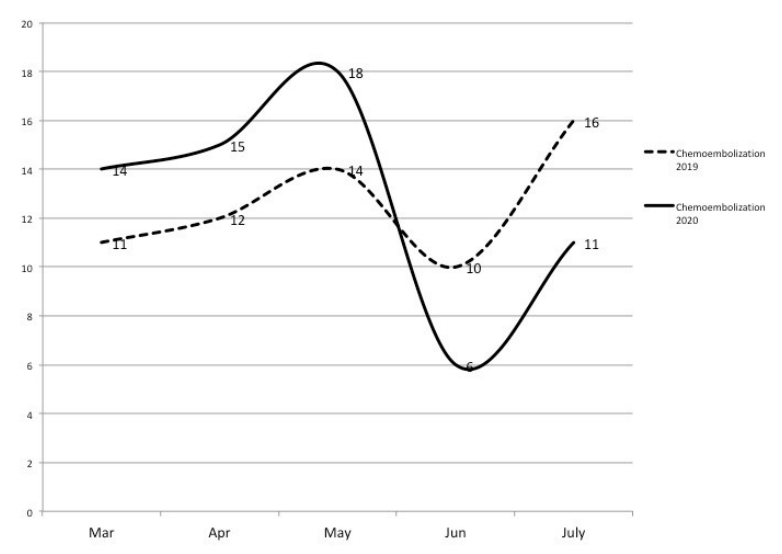

(c)

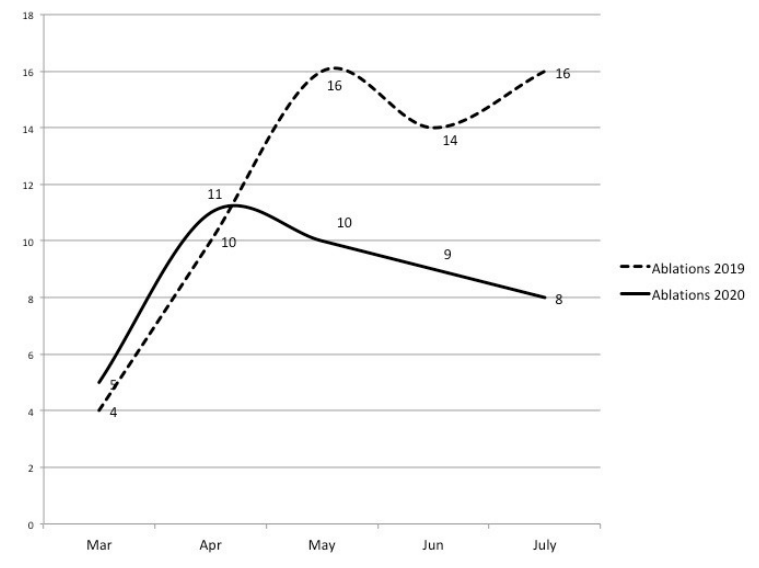

(b)

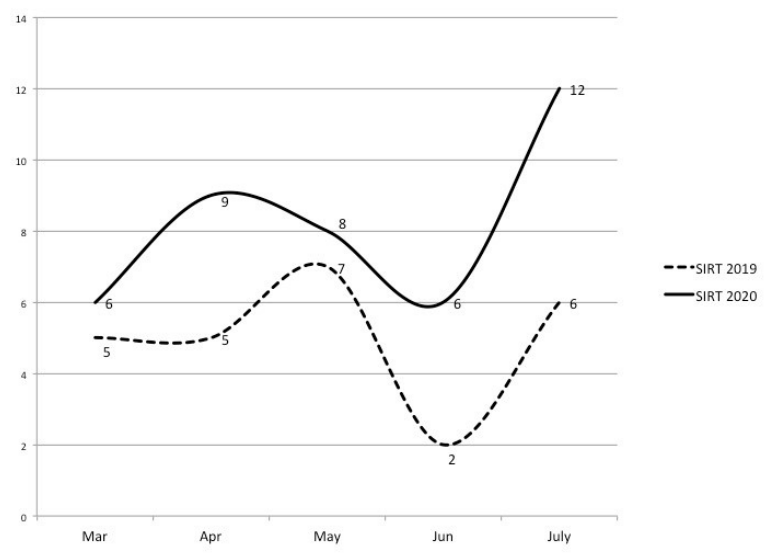

(d)

Figure 1. Liver oncologic activity between March and July 2019 and 2020: number of patients discussed at MLTB (a), ablations (b), transarterial chemoembolizations (c) and SIRT (d).

During the same period of time, the number of percutaneous ablations decreased by $28.3 \%$ (from 60 procedures in 2019 to 43 procedures in 2020, Figure 1b), while TACE remained stable (63 procedures in 2019 and 64 in 2020, Figure 1c). On the other hand, the number of SIRT treatments increased by $64 \%$, from 25 procedures in 22 patients in 2019 to 41 procedures in 36 patients in 2020 (Figure 1d).

\subsection{Patients' Characteristics}

Overall, $31(75.6 \%)$ procedures were performed in primary lesions in 2020 (mostly HCC), compared to 14 procedures (56\%) in 2019. Table 1.

Main demographic and clinical data of patients treated with SIRT are reported in

According to the Barcelona Clinic of Liver Cancer (BCLC) staging system [5], over 50\% of HCC patients were in the intermediate stage (BCLC B), while approximately one-third of cases were in the advanced stage (BCLC C) due to intrahepatic macrovascular invasion (Table 1). No early-stage HCC patients underwent SIRT between March and July 2020, compared to three $(25 \%)$ cases treated in $2019(p=0.04)$. 
Table 1. Data of treated patients who underwent SIRT in March-July period: comparison between 2019 and 2020.

\begin{tabular}{|c|c|c|c|c|}
\hline & & 2019 & 2020 & $p$ \\
\hline Number of patients & & 22 & 36 & \\
\hline Gender & Male & $16(72.7)$ & $27(75.0)$ & 0.85 \\
\hline Age (years) & Mean \pm SD & $68.8 \pm 10.6$ & $67.1 \pm 11.1$ & 0.55 \\
\hline \multirow{2}{*}{ Type of tumor } & Primary & $14(63.6)$ & $27(75.0)$ & 0.36 \\
\hline & Metastatic & $8(36.4)$ & $9(25.0)$ & \\
\hline \multirow[t]{4}{*}{ Histotype } & HCC & $12(54.5)$ & $22(61.1)$ & 0.51 \\
\hline & ICC & $2(9.1)$ & $5(13.9)$ & \\
\hline & $\mathrm{mCRC}$ & $6(27.3)$ & $6(16.7)$ & \\
\hline & Other & $2(9.1) *$ & $3(8.3)^{* *}$ & \\
\hline \multirow[t]{3}{*}{ BCLC staging (HCC) } & A & $3(25)$ & $0(0)$ & 0.04 \\
\hline & $\mathrm{B}$ & $6(50)$ & $14(63.6)$ & \\
\hline & $\mathrm{C}$ & $3(25)$ & $8(36.4)$ & \\
\hline \multirow[t]{3}{*}{ TNM staging (iCC) } & III & $0(0)$ & $4(80)$ & 0.03 \\
\hline & IVa & $2(100)$ & $0(0)$ & \\
\hline & $\mathrm{IVb}$ & $0(0)$ & $1(20)$ & \\
\hline \multirow{4}{*}{$\begin{array}{l}\text { Treatment line } \\
\text { (metastases) }\end{array}$} & First & $2(25)$ & $0(0)$ & 0.23 \\
\hline & Second & $3(37.5)$ & $3(33.3)$ & \\
\hline & Third & $3(37.5)$ & $6(66.7)$ & \\
\hline & Segmental & $2(9.1)$ & $4(11.1)$ & 0.78 \\
\hline \multirow[t]{3}{*}{ Type of procedure } & Unilobar & $16(72.7)$ & $23(63.9)$ & \\
\hline & Bilobar & $4(18.2)$ & $9(25)$ & \\
\hline & Yttrium-90 resin & $18(81.8)$ & $26(72.2)$ & 0.57 \\
\hline \multirow[t]{2}{*}{ Type of spheres } & Yttrium-90 glass & $2(9.1)$ & $3(8.3)$ & \\
\hline & Holmium-166 & $2(9.1)$ & $7(19.5)$ & \\
\hline
\end{tabular}

SIRT in iCC was performed as first-line treatment in two cases, and after first-line chemotherapy in the remaining cases, either as consolidation after radiological disease control $(n=3)$ or at progression $(n=2)$.

Metastatic lesions included mostly patients with liver-only or liver-dominant colorectal cancer metastases (mCRC). In 2019, two cases with neuroendocrine and medullary thyroid carcinoma metastases, respectively, underwent SIRT as first-line treatment modality, whereas all the other cases were treated after failure of second- or third-line systemic chemotherapy.

\subsection{Treatment}

Treatment modalities did not differ significantly comparing 2019 and 2020 (Table 1); the majority of procedures were performed as lobar procedures, with approximately $20 \%$ of cases requiring bilobar treatment. Patients were mostly treated with Yttrium-90 (Y-90)labeled resin microspheres, although in 2020, the number of procedures performed using Holmium-166-labeled microspheres increased (19.5\% in 2020 compared to $9.1 \%$ in 2019).

\subsection{Tumor Response}

No complications were observed after SIRT, and patients were discharged 24-48 h after treatment, according to our institutional policies.

Radiological outcomes were evaluated only for patients treated in 2020 and were available in $30 / 36(83.3 \%)$ patients. Considering the best radiological response, the objective response rate was $56.7 \%(17 / 30)$ and the disease control rate was $72.2 \%$, with four patients showing progressive disease early after treatment (Table 2 ). The best radiological response was registered 1-6 months after treatment (mean $\pm \mathrm{SD}, 3.07 \pm 1.46$ months). 
Table 2. Best radiological response according to tumor type in patients treated in 2020.

\begin{tabular}{cccccc}
\hline Tumor Type & Patients & CR & PR & SD & PD \\
\hline HCC $(n=22)$ & 18 & $4(22.2)$ & $9(50)$ & $3(16.7)$ & $2(11.1)$ \\
ICC $(n=5)$ & 5 & $1(20)$ & 0 & $4(80)$ & 0 \\
mCRC $(n=6)$ & 5 & $1(20)$ & 0 & $2(40)$ & $2(40)$ \\
Other $*(n=3)$ & 2 & $1(50)$ & $1(50)$ & 0 & 0 \\
Overall $(n=36)$ & 30 & $7(23.3)$ & $10(33.3)$ & $9(30)$ & $4(13.3)$ \\
\hline
\end{tabular}

When not otherwise specified, data are given as numbers (and percentages). ${ }^{*}$ Includes: renal cell carcinoma $(n=1)$, melanoma $(n=1)$ and lung cancer $(n=1)$.

\section{Discussion}

During the first wave of COVID-19 pandemic, oncologic patients suffered from a sudden limitation in surgical procedures and percutaneous ablations, reduced access to more demanding systemic therapies requiring hospitalization or close monitoring and limited availability of clinical trials [1-4]. In our experience, in this context, despite the overall reduction in the number of referrals and in the number of LDTs requiring anesthesiological support (such as percutaneous ablation), SIRT increased by $64 \%$ compared to the same interval of time of the previous year.

SIRT is safe and well-tolerated, even in more fragile and elderly patients [17]; no complications were observed in our series and all patients were discharged within $48 \mathrm{~h}$ after the procedure, according to our hospital policy. Moreover, SIRT is highly flexible; it can be indicated in a number of primary and secondary radiosensitive liver tumors [9-14], and it does not preclude other concomitant or subsequent systemic or surgical treatments. The latter represented a highly appealing feature during the COVID-19 breakthrough, allowing doctors to control tumor progression or even reduce the tumor load while patients were waiting for surgical evaluation or access to other therapies.

\subsection{Indications for SIRT}

The majority of the procedures performed in 2020 involved patients with primary liver lesions (75.6\% compared to $56 \%$ in 2019), with most of all HCC in the intermediate and advanced stages.

\subsubsection{Hepatocellular Carcinoma}

According to the national recommendations, during the lockdown, priority was given to oncologic patients at risk of rapid progression. Treatments of early-stage HCC patients were thus often postponed.

Meanwhile, clinical trials investigating new systemic drugs in intermediate/advanced stage HCC were temporarily suspended. Considering the toxicity of the standard-of-care systemic therapies and the difficulties in monitoring patients under treatment, SIRT represented a valid option in BCLC C patients with liver-limited disease (such as patients with intrahepatic macrovascular invasion) and in BCLC B patients with a tumor extension considered unfit for TACE.

In this setting, large prospective randomized studies have failed in demonstrating the superiority of SIRT, alone or in combination with systemic therapy, over the standard-ofcare therapy Sorafenib [18-20]. However, the retrospective, non-inferiority analysis of these large trials (NEMESIS trial) showed that SIRT offered similar survival rates to Sorafenib, with reduced toxicity and improved quality of life [21].

Moreover, the design of these trials has been criticized [22], while deeper knowledge was gained on SIRT indications and techniques. Today, it is generally recognized that macrovascular invasion involving the main portal trunk should be an exclusion criterion for SIRT [23,24], and that baseline liver function strongly affects treatment outcomes [23,25]. Moreover, we have learned that tumor targeting and personalized dosimetry strongly impact the clinical outcomes of SIRT. The recent prospective Dosisphere trial set a new 
standard for dosimetry in intermediate/advanced HCC using Y-90 glass microspheres [26] and re-opened the debate on the role of SIRT in intermediate/advanced HCC [14].

Regarding intermediate-stage HCC, little data are available comparing SIRT to TACE, and small randomized studies have not demonstrated the superiority of one treatment over the other [27], although the number of treatments needed to achieve similar tumor response may be lower for SIRT compared to TACE.

Nonetheless, prospective studies and propensity score-matched analyses have shown that, compared to TACE, SIRT is better tolerated and can be associated with higher rates of complete response and downstaging to transplantation and longer time to progression $[9,28,29]$. Thus, SIRT is becoming appealing in potentially surgical patients or in intermediate-stage patients with tumors involving multiple liver segments.

Over the past few years, SIRT has also emerged as a potentially curative therapy in early-stage HCC. A recent multicenter prospective study reported an $88 \%$ objective response rate, with long-lasting tumor response in $62 \%$ of patients and $86.6 \%$ of patients with a 3-year survival rate, which is comparable to other curative treatments [30]. In the present series, non-early-stage HCCs were treated with SIRT between March and July 2020, probably as a result of the above-mentioned limitations for patients at lower risk of rapid progression.

\subsubsection{Intrahepatic Cholangiocarcinoma}

Our series included 13.9\% inoperable iCC patients treated with SIRT in 2020. Multiple retrospective and prospective series reported good tolerability and objective response rates, with 12-14 months median OS [31,32], comparable to the data reported after TACE [33]. The role of SIRT in iCC is yet not well-defined [7]. Indeed, our series included patients with stable disease after first-line chemotherapy, as well as patients progressing after resection and chemotherapy. SIRT was also performed as first-line treatment in two iCC patients with contraindications to systemic therapies.

Of interest, in a prospective phase 2 study, Edeline et al. showed a longer OS (median 22 months) in selected iCC patients treated with a combination of standard chemotherapy and SIRT in first-line therapy [34]. The longer OS was mainly because $22 \%$ of patients were downstaged to resection after this combination therapy, with an $88.9 \%$ survival rate 2 years after surgery. The majority of downstaged patients had liver-only disease, with unifocal lesion confined to one hemiliver and no cirrhosis. Thus, in this highly selected "potentially resectable" population, an intensive treatment regimen combing chemotherapy and SIRT could help reducing the tumor load while inducing contralateral liver lobe hypertrophy and ultimately allowing for safe $\mathrm{R} 0$ resection.

\subsubsection{Liver Metastases}

Numerous radiosensitive metastatic lesions may be treated with SIRT, alone or in combination with personalized therapies [35].

In the present series, most of our metastatic patients were affected by $\mathrm{mCRC}$ and were treated after the failure of second- or third-line systemic therapy. After the failure of large, randomized studies investigating the role of SIRT as first-line therapy [36], European guidelines consider SIRT as a valid treatment option in unresectable patients with liveronly or liver-dominant oligometastatic $\mathrm{mCRC}$, failing all available systemic treatment options [8]. However, in clinical practice, SIRT is increasingly used also in earlier stages, as consolidation after first- or second-line therapies or to allow for some time of chemoholiday [11]. The concept of "chemo-holiday" is of particular interest in the context of this pandemic, for patients with preserved liver function, in need for some wash out from drug toxicity, for whom SIRT is able to control the tumor progression with good tolerability, provided adequate tumor targeting and dosimetry.

In fact, for HCC and in $\mathrm{mCRC}$, the tumor response is strictly related to the tumorabsorbed dose, while the liver toxicity should be limited by preliminary assessment of the healthy liver-absorbed dose, which should not exceed certain thresholds [37]. 


\subsection{Logistic Challenges}

Compared to other LDTs, SIRT represents a more complex procedure, requiring at least two visits, a solid expertise and a strong interdisciplinary collaboration, which involves referring physicians, interventional radiologists, nuclear medicine specialists and medical physicists. This complexity may be even more relevant in the context of the COVID-19 pandemic.

\subsubsection{Interdisciplinary Communication}

With the lockdown, tumor boards were converted into virtual meetings. This allowed for a better organization of the meeting, since the cases to be presented were prepared and, when possible, shared in advanced, for instance uploading into the system examinations performed in other institutions prior to the meeting.

Our university hospital is divided into two different facilities approximately $4 \mathrm{~km}$ apart. The virtual boards eliminated the logistic problems related to this distance, facilitating the attendance to all the involved specialists, in particular the colleagues from the Nuclear Medicine Department. The more regular involvement of the nuclear medicine specialists could have had an impact in the observed increase in SIRT treatments.

Due to these beneficial effects, our tumor boards were maintained virtually after the end of the lockdown.

\subsubsection{Hospitalization and Resource Optimization}

Prior to definitive treatment, patients are evaluated using some of the following techniques: angiographic mapping, arterial embolization, injection of a radiotracer (or scout dose with Holmium-166 labeled particles) and assessment of its distribution with SPECT/SPECTCT. This preliminary evaluation is needed to identify possible contraindications to SIRT (such as extrahepatic uptake, high lung shunt fraction and poor tumor targeting) and to calculate the activity to be delivered to tumor. Then, the calculated dose is ordered specifically for each patient on a specific date, and its administration is typically performed after 1-3 weeks. This usually implies two separate hospitalizations; for instance, in our institution, at least 2 days of hospitalization are required for each procedure, mainly because of safety concerns and reimbursement issues.

International surveys have described the impact of COVID-19 in nuclear medicine activity, reporting decreases in diagnostic and therapeutic procedures, and in some countries, insufficient supplies of essential materials, including Tc-99m [38-40]. Although COVID19 also affected this activity in our institution, the Nuclear Medicine Department was maintained as a COVID-19-free ward, and we were able to increase the number of SIRT procedures by reserving two beds each week specifically for both the diagnostic work up and the SIRT treatment, identifying specific days of the week (Tuesday and Thursday, respectively) in order to maintain an efficient turnover.

The pandemic has stimulated an analysis on resource consumption and how to optimize it, starting from the duration of hospitalization. In some countries, SIRT is safely performed as an outpatient procedure [41,42], thanks to the utilization of the transradial arterial access that allows for faster patient mobilization $[43,44]$; the pandemic represents the opportunity to discuss national and local policies and push forward the idea of "ambulatory" SIRT.

When using resin microspheres, same-day SIRT may represent another option to reduce the need for hospitalization, in well-selected patients [45]. Recent papers have also suggested that the preliminary diagnostic work up could be avoided in specific situations, such as patients with small HCC and without TIPS, who are candidates for radiation segmentectomy, since in these conditions, the risk of clinically significant lung shunting is minimal, tumor targeting and extrahepatic uptake can be ruled out using intraprocedural cone-beam CT and dosimetry can be calculated on the basis of the whole liver and target liver volumes on baseline cross-sectional imaging and intraprocedural cone-beam CT [46,47]. 
In the future, this treatment could be further simplified by introducing "off-the-shelf" vials. The labeled beads have a specific daily decay and can be potentially used any day of the week, once the desired activity to be administered is obtained. SIRT could then become a more expedited treatment, similar to other transarterial therapies. However, to limit the expenses, "off-the-shelf SIRT" implies a relatively high volume of SIRT treatments and rapid turnover.

\section{Conclusions}

In our experience, the first wave of the COVID-19 pandemic witnessed an increased demand for SIRT. In a scenario characterized by delays in oncologic referrals and surgical procedures, limited access to care and difficulties in monitoring side effects of systemic therapies, SIRT represents a safe, manageable and effective treatment to control tumor progression in both primary and secondary liver lesions.

Efficacy and manageability of SIRT will further improve by simplifying the treatment workflow, developing user-friendly and reliable tools for personalized dosimetry and improving interdisciplinary communication.

Author Contributions: Conceptualization, G.B., A.C.T., L.C., D.V. and R.C. (Roberto Cioni); Data curation, I.B., G.B., E.B., F.B., R.C. (Rosa Cervelli) and T.D.; Formal analysis, G.L., R.C. (Rosa Cervelli) and L.C.; Investigation, I.B., G.B., A.C.T., E.B., G.L., F.B. and T.D.; Methodology, F.B.; Supervision, D.V. and R.C. (Roberto Cioni); Validation, I.B., G.B., E.B., G.L., F.B., R.C. (Rosa Cervelli), T.D., L.C., D.V. and R.C. (Roberto Cioni); Visualization, A.C.T.; Writing-original draft, I.B., A.C.T., G.L. and T.D.; Writing-review and editing, I.B., E.B., R.C. (Rosa Cervelli), L.C., D.V. and R.C. (Roberto Cioni). All authors have read and agreed to the published version of the manuscript.

Funding: This research received no external funding.

Institutional Review Board Statement: Ethical review and approval were waived for this study, since the study refers to analysis of numbers of procedures and it represents a review of the indications of the procedure.

Informed Consent Statement: Patient consent was waived.

Data Availability Statement: The data presented in this study are available on request from the corresponding author.

Conflicts of Interest: Irene Bargellini received honoraria for speaker activities and for Advisory Boards from Sirtex Medical Europe GmbH, Biocompatibles UK LTD, Boston Scientific and Terumo Europe NV. G.B. received honoraria for speaker activities from Terumo Europe NV. Laura Crocetti received honoraria for speaker activities from Terumo Europe NV. The remaining authors declare no conflict of interest.

\section{References}

1. Bulki, T.K. Cancer Guidelines during the COVID-19 Pandemic. Lancet Oncol. 2020, 21, 629-630.

2. Bartlett, D.L.; Howe, J.R.; Chang, G.; Crago, A.; Hogg, M.; Karakousis, G.; Levine, E.; Maker, A.; Mamounas, E.; McGuire, K.; et al. Management of Cancer Surgery Cases During the COVID-19 Pandemic: Considerations. Ann. Surg. Oncol. 2020, 27, 1717-1720. [CrossRef]

3. Jazieh, A.R.; Akbulut, H.; Curigliano, G.; Rogado, A.; Alsharm, A.A.; Razis, E.D.; Mula-Hussain, L.; Errihani, H.; Khattak, A.; De Guzman, R.B.; et al. International Research Network on COVID-19 Impact on Cancer Care. Impact of the COVID-19 Pandemic on Cancer Care: A Global Collaborative Study. JCO Glob. Oncol. 2020, 6, 1428-1438. [CrossRef]

4. Torzilli, G.; Viganò, L.; Galvanin, J.; Castoro, C.; Quagliuolo, V.; Spinelli, A.; Zerbi, A.; Donadon, M.; Montorsi, M.; COVIDSURGE-ITA group. A Snapshot of Elective Oncological Surgery in Italy during COVID-19 Emergency: Pearls, Pitfalls, and Perspectives. Ann. Surg. 2020, 272, e112-e117. [CrossRef]

5. European Association for the Study of the Liver. EASL Clinical Practice Guidelines: Management of hepatocellular carcinoma. J. Hepatol. 2018, 69, 182-236. [CrossRef]

6. Llovet, J.M.; Villanueva, A.; Marrero, J.A.; Schwartz, M.; Meyer, T.; Galle, P.R.; Lencioni, R.; Greten, T.F.; Kudo, M.; Mandrekar, S.J.; et al. AASLD Panel of Experts on Trial Design in HCC. Trial Design and Endpoints in Hepatocellular Carcinoma: AASLD Consensus Conference. Hepatology 2021, 73 (Suppl. 1), 158-191. [CrossRef] 
7. Bridgewater, J.; Galle, P.R.; Khan, S.A.; Llovet, J.M.; Park, J.W.; Patel, T.; Pawlik, T.M.; Gores, G.J. Guidelines for the diagnosis and management of intrahepatic cholangiocarcinoma. J. Hepatol. 2014, 60, 1268-1289. [CrossRef]

8. Van Cutsem, E.; Cervantes, A.; Adam, R.; Sobrero, A.; Van Krieken, J.H.; Aderka, D.; Aranda Aguilar, E.; Bardelli, A.; Benson, A.; Bodoky, G.; et al. ESMO consensus guidelines for the management of patients with metastatic colorectal cancer. Ann. Oncol. 2016, 27, 1386-1422. [CrossRef]

9. Qadan, M.; Fong, Z.V.; Delman, A.M.; Gabr, A.; Salem, R.; Shah, S.A. Review of Use of Y90 as a Bridge to Liver Resection and Transplantation in Hepatocellular Carcinoma. J. Gastrointest. Surg. 2021. Online ahead of print. [CrossRef] [PubMed]

10. Edeline, J.; Lamarca, A.; McNamara, M.G.; Jacobs, T.; Hubner, R.A.; Palmer, D.; Koerkamp, B.G.; Johnson, P.; Guiu, B.; Valle, J.W. Locoregional therapies in patients with intrahepatic cholangiocarcinoma: A systematic review and pooled analysis. Cancer. Treat. Rev. 2021, 99, 102258. [CrossRef]

11. Jeyarajah, D.R.; Doyle, M.B.M.; Espat, N.J.; Hansen, P.D.; Iannitti, D.A.; Kim, J.; Thambi-Pillai, T.; Visser, B.C. Role of yttrium-90 selective internal radiation therapy in the treatment of liver-dominant metastatic colorectal cancer: An evidence-based expert consensus algorithm. J. Gastrointest. Oncol. 2020, 11, 443-460. [CrossRef]

12. Salem, R.; Padia, S.A.; Lam, M.; Bell, J.; Chiesa, C.; Fowers, K.; Hamilton, B.; Herman, J.; Kappadath, S.C.; Leung, T.; et al. Clinical and dosimetric considerations for Y90: Recommendations from an international multidisciplinary working group. Eur. J. Nucl. Med. Mol. Imaging 2019, 46, 1695-1704. [CrossRef]

13. Levillain, H.; Bagni, O.; Deroose, C.M.; Dieudonné, A.; Gnesin, S.; Grosser, O.S.; Kappadath, S.C.; Kennedy, A.; Kokabi, N.; Liu, D.M.; et al. International recommendations for personalised selective internal radiation therapy of primary and metastatic liver diseases with yttrium-90 resin microspheres. Eur. J. Nucl. Med. Mol. Imaging 2021, 48, 1570-1584. [CrossRef]

14. Garin, E.; Palard, X.; Rolland, Y. Personalised Dosimetry in Radioembolisation for HCC: Impact on Clinical Outcome and on Trial Design. Cancers 2020, 12, 1557. [CrossRef]

15. Eisenhauer, E.A.; Therasse, P.; Bogaerts, J.; Schwartz, L.H.; Sargent, D.; Ford, R.; Dancey, J.; Arbuck, S.; Gwyther, S.; Mooney, M.; et al. New response evaluation criteria in solid tumours: Revised RECIST guideline (version 1.1). Eur. J. Cancer 2009, 45, 228-247. [CrossRef]

16. Lencioni, R.; Llovet, J.M. Modified RECIST (mRECIST) assessment for hepatocellular carcinoma. Semin. Liver Dis. 2010, 30, 52-60. [CrossRef]

17. Golfieri, R.; Bilbao, J.I.; Carpanese, L.; Cianni, R.; Gasparini, D.; Ezziddin, S.; Paprottka, P.M.; Fiore, F.; Cappelli, A.; European Network on Radioembolization with Yttrium-90 Microspheres (ENRY) Study Collaborators; et al. Comparison of the survival and tolerability of radioembolization in elderly vs. younger patients with unresectable hepatocellular carcinoma. J. Hepatol. 2013, 59, 753-761. [CrossRef] [PubMed]

18. Vilgrain, V.; Pereira, H.; Assenat, E.; Guiu, B.; Ilonca, A.D.; Pageaux, G.P.; Sibert, A.; Bouattour, M.; Lebtahi, R.; SARAH Trial Group; et al. Efficacy and safety of selective internal radiotherapy with yttrium-90 resin microspheres compared with sorafenib in locally advanced and inoperable hepatocellular carcinoma (SARAH): An open-label randomised controlled phase 3 trial. Lancet Oncol. 2017, 18, 1624-1636. [CrossRef]

19. Chow, P.K.H.; Gandhi, M.; Tan, S.B.; Khin, M.W.; Khasbazar, A.; Ong, J.; Choo, S.P.; Cheow, P.C.; Chotipanich, C.; Asia-Pacific Hepatocellular Carcinoma Trials Group; et al. SIRveNIB: Selective Internal Radiation Therapy Versus Sorafenib in Asia-Pacific Patients With Hepatocellular Carcinoma. J. Clin. Oncol. 2018, 36, 1913-1921. [CrossRef]

20. Ricke, J.; Klümpen, H.J.; Amthauer, H.; Bargellini, I.; Bartenstein, P.; de Toni, E.N.; Gasbarrini, A.; Pech, M.; Peck-Radosavljevic, M.; Popovič, P.; et al. Impact of combined selective internal radiation therapy and sorafenib on survival in advanced hepatocellular carcinoma. J. Hepatol. 2019, 71, 1164-1174. [CrossRef]

21. Venerito, M.; Pech, M.; Canbay, A.; Donghia, R.; Guerra, V.; Chatellier, G.; Pereira, H.; Gandhi, M.; Malfertheiner, P.; Chow, P.K.H.; et al. NEMESIS: Noninferiority, Individual-Patient Metaanalysis of Selective Internal Radiation Therapy with $90 \mathrm{Y}$ Resin Microspheres Versus Sorafenib in Advanced Hepatocellular Carcinoma. J. Nucl. Med. 2020, 61, 1736-1742. [CrossRef] [PubMed]

22. Sposito, C.; Mazzaferro, V. The SIRveNIB and SARAH trials, radioembolization vs. sorafenib in advanced HCC patients: Reasons for a failure, and perspectives for the future. Hepatobiliary Surg. Nutr. 2018, 7, 487-489. [CrossRef]

23. Spreafico, C.; Sposito, C.; Vaiani, M.; Cascella, T.; Bhoori, S.; Morosi, C.; Lanocita, R.; Romito, R.; Chiesa, C.; Maccauro, M.; et al. Development of a prognostic score to predict response to Yttrium-90 radioembolization for hepatocellular carcinoma with portal vein invasion. J. Hepatol. 2018, 68, 724-732. [CrossRef]

24. Bargellini, I.; Scalise, P.; Boni, G.; Traino, C.A.; Bozzi, E.; Lorenzoni, G.; Crocetti, L.; Cioni, R. Yttrium-90 Radioembolization for Hepatocellular Carcinoma with Portal Vein Invasion: Validation of the Milan Prognostic Score. J. Vasc. Interv. Radiol. 2020, 31, 2028-2032. [CrossRef]

25. Hermann, A.L.; Dieudonné, A.; Ronot, M.; Sanchez, M.; Pereira, H.; Chatellier, G.; Garin, E.; Castera, L.; Lebtahi, R.; SARAH Trial Group; et al. Relationship of Tumor Radiation-absorbed Dose to Survival and Response in Hepatocellular Carcinoma Treated with Transarterial Radioembolization with 90 Y in the SARAH Study. Radiology 2020, 296, 673-684. [CrossRef] [PubMed]

26. Garin, E.; Tselikas, L.; Guiu, B.; Chalaye, J.; Edeline, J.; de Baere, T.; Assenat, E.; Tacher, V.; Robert, C.; DOSISPHERE-01 Study Group; et al. Personalised versus standard dosimetry approach of selective internal radiation therapy in patients with locally advanced hepatocellular carcinoma (DOSISPHERE-01): A randomised, multicentre, open-label phase 2 trial. Lancet Gastroenterol. Hepatol. 2021, 6, 17-29. [CrossRef] 
27. Casadei Gardini, A.; Tamburini, E.; Iñarrairaegui, M.; Frassineti, G.L.; Sangro, B. Radioembolization versus chemoembolization for unresectable hepatocellular carcinoma: A meta-analysis of randomized trials. Onco. Targets Ther. 2018, 11, 7315-7321. [CrossRef]

28. Padia, S.A.; Johnson, G.E.; Horton, K.J.; Ingraham, C.R.; Kogut, M.J.; Kwan, S.; Vaidya, S.; Monsky, W.L.; Park, J.O.; Bhattacharya, R.; et al. Segmental Yttrium-90 Radioembolization versus Segmental Chemoembolization for Localized Hepatocellular Carcinoma: Results of a Single-Center, Retrospective, Propensity Score-Matched Study. J. Vasc. Interv. Radiol. 2017, 28, 777-785.e1. [CrossRef]

29. Gabr, A.; Kulik, L.; Mouli, S.; Riaz, A.; Ali, R.; Desai, K.; Mora, R.A.; Ganger, D.; Maddur, H.; Flamm, S.; et al. Liver Transplantation Following Yttrium-90 Radioembolization: 15-Year Experience in 207-Patient Cohort. Hepatology 2021, 73, 998-1010. [CrossRef]

30. Salem, R.; Johnson, G.E.; Kim, E.; Riaz, A.; Bishay, V.; Boucher, E.; Fowers, K.; Lewandowski, R.; Padia, S.A. Yttrium-90 Radioembolization for the Treatment of Solitary, Unresectable HCC: The LEGACY Study. Hepatology 2021. Online ahead of print. [CrossRef]

31. Bargellini, I.; Mosconi, C.; Pizzi, G.; Lorenzoni, G.; Vivaldi, C.; Cappelli, A.; Vallati, G.E.; Boni, G.; Cappelli, F.; Paladini, A.; et al. Yttrium-90 Radioembolization in Unresectable Intrahepatic Cholangiocarcinoma: Results of a Multicenter Retrospective Study. Cardiovasc. Interv. Radiol. 2020, 43, 1305-1314. [CrossRef] [PubMed]

32. Helmberger, T.; Golfieri, R.; Pech, M.; Pfammatter, T.; Arnold, D.; Cianni, R.; Maleux, G.; Munneke, G.; On behalf of the CIRT Steering Committee; On behalf of the CIRT Principal Investigators; et al. Clinical Application of Trans-Arterial Radioembolization in Hepatic Malignancies in Europe: First Results from the Prospective Multicentre Observational Study CIRSE Registry for SIR-Spheres Therapy (CIRT). Cardiovasc. Interv. Radiol. 2021, 44, 21-35. [CrossRef] [PubMed]

33. Mosconi, C.; Solaini, L.; Vara, G.; Brandi, N.; Cappelli, A.; Modestino, F.; Cucchetti, A.; Golfieri, R. Transarterial Chemoembolization and Radioembolization for Unresectable Intrahepatic Cholangiocarcinoma-a Systemic Review and Meta-Analysis. Cardiovasc. Interv. Radiol. 2021, 44, 728-738. [CrossRef] [PubMed]

34. Edeline, J.; Touchefeu, Y.; Guiu, B.; Farge, O.; Tougeron, D.; Baumgaertner, I.; Ayav, A.; Campillo-Gimenez, B.; Beuzit, L.; Pracht, M.; et al. Radioembolization Plus Chemotherapy for First-line Treatment of Locally Advanced Intrahepatic Cholangiocarcinoma: A Phase 2 Clinical Trial. JAMA Oncol. 2020, 6, 51-59. [CrossRef]

35. Braat, A.J.A.T.; Bruijnen, R.C.G.; van Rooij, R.; Braat, M.N.G.J.A.; Wessels, F.J.; van Leeuwaarde, R.S.; van Treijen, M.J.C.; de Herder, W.W.; Hofland, J.; Tesselaar, M.E.T.; et al. Additional holmium-166 radioembolisation after lutetium-177-dotatate in patients with neuroendocrine tumour liver metastases (HEPAR PLuS): A single-centre, single-arm, open-label, phase 2 study. Lancet Oncol. 2020, 21, 561-570. [CrossRef]

36. Wasan, H.S.; Gibbs, P.; Sharma, N.K.; Taieb, J.; Heinemann, V.; Ricke, J.; Peeters, M.; FOXFIRE Trial Investigators; SIRFLOX Trial Investigators; FOXFIRE-Global Trial Investigators; et al. First-line selective internal radiotherapy plus chemotherapy versus chemotherapy alone in patients with liver metastases from colorectal cancer (FOXFIRE, SIRFLOX, and FOXFIRE-Global): A combined analysis of three multicentre, randomised, phase 3 trials. Lancet Oncol. 2017, 18, 1159-1171. [CrossRef] [PubMed]

37. Alsultan, A.A.; van Roekel, C.; Barentsz, M.W.; Smits, M.L.J.; Kunnen, B.; Koopman, M.; Bruijnen, R.C.G.; de Keizer, B.; Lam, M.G.E.H. Dose-response and dose-toxicity relationships for yttrium-90 glass radioembolization in patients with colorectal cancer liver metastases. J. Nucl. Med. 2021. Online ahead of print. [CrossRef]

38. Freudenberg, L.S.; Paez, D.; Giammarile, F.; Cerci, J.; Modiselle, M.; Pascual, T.N.B.; El-Haj, N.; Orellana, P.; Pynda, Y.; Carrió, I.; et al. Global Impact of COVID-19 on Nuclear Medicine Departments: An International Survey in April 2020. J. Nucl. Med. 2020, 61, 1278-1283. [CrossRef]

39. Annunziata, S.; Albano, D.; Laudicella, R.; Bauckneht, M. Young Committee of the Italian Association of Nuclear Medicine (AIMN). Surveys on COVID-19 in nuclear medicine: What happened and what we learned. Clin. Transl. Imaging 2020, 24, 1-3. [CrossRef]

40. Giammarile, F.; Delgado Bolton, R.C.; El-Haj, N.; Freudenberg, L.S.; Herrmann, K.; Mikhail, M.; Morozova, O.; Orellana, P.; Pellet, O.; Estrada L, E.; et al. Changes in the global impact of COVID-19 on nuclear medicine departments during 2020: An international follow-up survey. Eur. J. Nucl. Med. Mol. Imaging 2021, 19, 1-13, Online ahead of print. [CrossRef]

41. Hickey, R.M.; Maslowski, J.M.; Aaltonen, E.T.; Horn, J.C.; Patel, A.; Sista, A.K.; Gross, J.S. Yttrium-90 Radioembolization in the Office-Based Lab. J. Vasc. Interv. Radiol. 2020, 31, 1442-1448. [CrossRef] [PubMed]

42. Aberle, S.; Kenkel, D.; Becker, A.S.; Puippe, G.; Burger, I.; Schaefer, N.; Pfammatter, T. Outpatient Yttrium-90 microsphere radioembolization: Assessment of radiation safety and quantification of post-treatment adverse events causing hospitalization. Radiol. Med. 2020, 125, 971-980. [CrossRef]

43. Liu, L.B.; Cedillo, M.A.; Bishay, V.; Ranade, M.; Patel, R.S.; Kim, E.; Nowakowski, S.F.; Lookstein, R.A.; Fischman, A.M. Patient Experience and Preference in Transradial versus Transfemoral Access during Transarterial Radioembolization: A Randomized Single-Center Trial. J. Vasc. Interv. Radiol. 2019, 30, 414-420. [CrossRef] [PubMed]

44. Loewenstern, J.; Welch, C.; Lekperic, S.; Bishay, V.; Ranade, M.; Patel, R.S.; Kim, E.; Nowakowski, F.S.; Lookstein, R.A.; Fischman, A.M. Patient Radiation Exposure in Transradial versus Transfemoral Yttrium-90 Radioembolization: A Retrospective Propensity Score-Matched Analysis. J. Vasc. Interv. Radiol. 2018, 29, 936-942. [CrossRef] [PubMed]

45. Elsayed, M.; Loya, M.; Galt, J.; Schuster, D.M.; Bercu, Z.L.; Newsome, J.; Brandon, D.; Benenati, S.; Behbahani, K.; Duszak, R.; et al. Same day yttrium-90 radioembolization with single photon emission computed tomography/computed 
tomography: An opportunity to improve care during the COVID-19 pandemic and beyond. World J. Gastrointest. Oncol. 2021, 13, 440-452. [CrossRef]

46. Gabr, A.; Ranganathan, S.; Mouli, S.K.; Riaz, A.; Gates, V.L.; Kulik, L.; Ganger, D.; Maddur, H.; Moore, C.; Hohlastos, E.; et al. Streamlining radioembolization in UNOS T1/T2 hepatocellular carcinoma by eliminating lung shunt estimation. J. Hepatol. 2020, 72, 1151-1158. [CrossRef] [PubMed]

47. Edeline, J.; Garin, E. Streamlining TARE or personalizing SIRT? Different philosophies to treat different HCCs with Yttrium-90 ... . J. Hepatol. 2020, 72, 1046-1048. [CrossRef] [PubMed] 